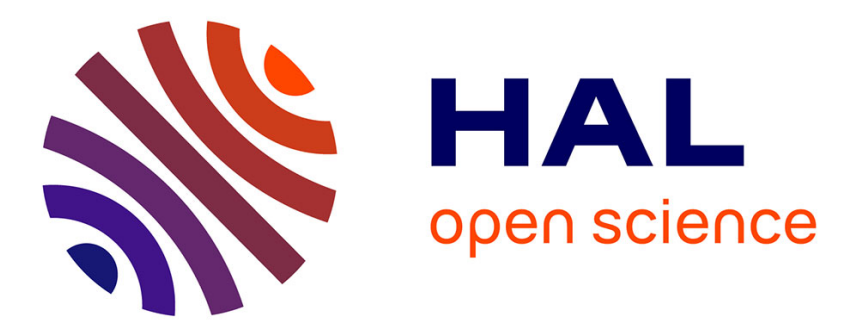

\title{
Hydromechanical loading and compressibility of fibrous reinforcements
}

\author{
Pierre Ouagne, Joel Breard, Tariq Ouahbi, Chung Hae Park, Abdelghani \\ Saouab, Sylvain Chatel
}

\section{- To cite this version:}

Pierre Ouagne, Joel Breard, Tariq Ouahbi, Chung Hae Park, Abdelghani Saouab, et al.. Hydromechanical loading and compressibility of fibrous reinforcements. International Journal of Materials Forming, 2008, pp.933-936. hal-00655505

\section{HAL Id: hal-00655505 https://hal.science/hal-00655505}

Submitted on 30 Dec 2011

HAL is a multi-disciplinary open access archive for the deposit and dissemination of scientific research documents, whether they are published or not. The documents may come from teaching and research institutions in France or abroad, or from public or private research centers.
L'archive ouverte pluridisciplinaire HAL, est destinée au dépôt et à la diffusion de documents scientifiques de niveau recherche, publiés ou non, émanant des établissements d'enseignement et de recherche français ou étrangers, des laboratoires publics ou privés. 


\title{
Hydromechanical loading and compressibility of fibrous reinforcements
}

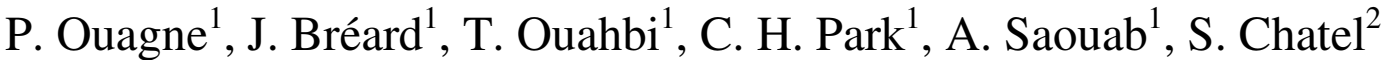

${ }^{1}$ Laboratoire d'ondes et de milieux complexes

Université du Havre, 53Rue de Prony

BP 54076058 Le Havre France

URL: www.univ-lehavre.fr

pierre.ouagne@univ-lehavre.fr

joel.breard@univ-lehavre.fr

tariq.ouahbi526@univ-lehavre.fr

chung-hae.park@univ-lehavre.fr

abdelghani.saouab@univ-lehavre.fr

${ }^{2}$ EADS France, 12 rue Pasteur,

BP 76, 92152 Suresnes, France

URL: $\underline{\text { www.eads.com }}$

sylvain.chatel@eads.net

\begin{abstract}
During the Resin Film Infusion Process (RFI), the resin flows through the fibrous medium under the stress created by a flexible membrane in the transverse direction of the reinforcement's plane. The compaction of the preforms and the flow of resin through the fibrous network take place simultaneously. There is, therefore, a coupled loading of the porous reinforcements. In order to better control this process, it is necessary to optimize resin pressure and fabric compression by using the appropriate simulating tools. It is also necessary to clarify which laws are suitable to model the process. To this objective, a new experimental device was set up to impose hydromechanical loadings to fibrous preforms. Results analyzing the hydromechanical couplings in saturated medium with flow rate conditions and a compression control with stress conditions are presented and discussed in this work. A model simulating infusion processes [1] has also been used to analyse the compressibility behaviour of the fibrous reinforcement by using an inverse method.
\end{abstract}

Key words: Infusion, Hydro-Mechanical loading, LCM Processes Compressibility, Inverse method

flow occur simultaneously and there is thus

\section{INTRODUCTION}

The need for manufacturing large composite parts in the field of the aeronautic industry is increasingly important. Processes of the Liquid Composite Molding (LCM) class are widely used. These processes such as Resin Transfer Molding (RTM) consist of injecting a liquid thermosetting resin through some layers of dry and shaped preform.

However, these processes are not well adapted in the case of large part manufacturing because of large tooling cost. Some void formation may also appear when the resin travels large distances as its viscosity may increase before the part is completely filled as a result of partial curing [2]. The infusion processes such as RFI [3] consists of transmitting a stress with a vacuum bag on a stack of semi-cured liquid resin film and dry preforms (Figure 1). The whole set up is generally placed in an autoclave to ensure the correct compression stress and to control the temperature cycle. The resin flows through the preform in the direction of the applied bag's stress. The reinforcement compressibility and the resin

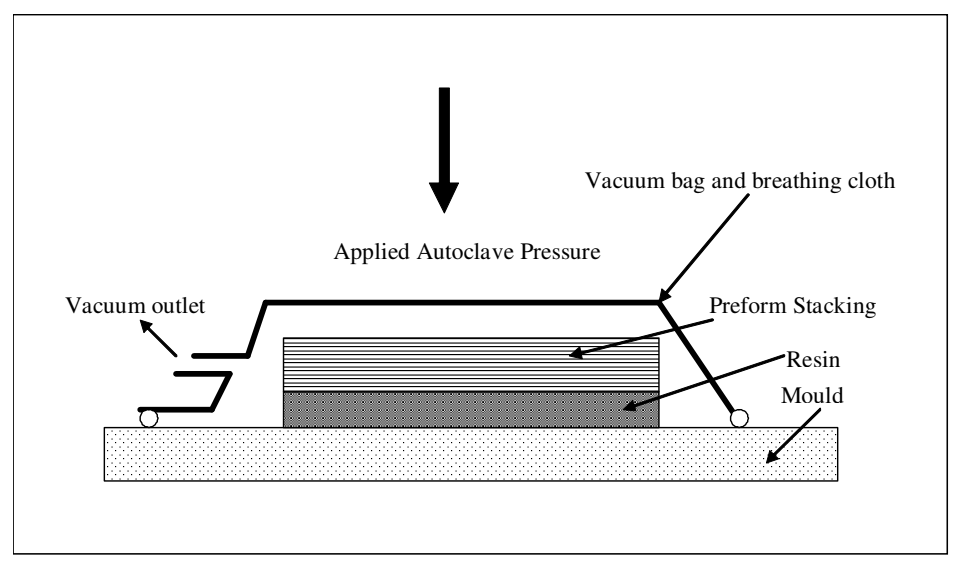

Fig.1. The Resin Film Infusion process

a mutual influence between the two "solid and liquid" phases.

A strong coupling between the reinforcement compaction and the resin flow takes place and needs to be taken into account for the modelling of the process.

Studies dealing with the modelling of resin infiltration in deformable preforms under different 
conditions have been published [4-6]. The fabric is supposed to be uniformly deformed in the direction of applied stress. In processes such as RFI, the principal resin flow and fabric deformation occur in the same direction. The resin pressure and the fabric compaction stress are not uniform within the thickness direction. The differential pressure and compaction stresses in the $z$ direction are taken into account in the modelling of the RFI process proposed by Ouahbi et al. [1] and Terzaghi's Law is used to couple the resin pressure and the mechanical stress imposed to the preform.

The previously mentioned models are based on experimentally determined material properties. The compressibility as well as the permeability behaviour of the preform is key entry parameter for the modelling of the process. The compressibility behaviour of the preform is most of the time modelled by empirical laws based on experimental observation. The Toll and Manson model [7] based on a power law formulation is frequently used.

$$
\sigma_{z}^{\prime}=a V_{f}^{b}
$$

where $\sigma^{\prime}$ is the compression stress, $a$ and $b$ are the coefficients of the power law and $V_{f}$ is the fibre volume fraction.

Merhi et al. [8] proposed a "physical" explanation based on the beam theory for the value of $b$ in the case of randomly aligned fibre bundles mat. For other types of reinforcement, the $b$ value is obtained from experimental compressibility curves. Cadinot [9] found $b$ values situated in the range 5-8 for mats, and in the range 9-14 for more ordered reinforcements such as UD or satin weaves. Moreover, the value of $b$ can be greatly affected by variation of the compression speed due to the viscoelastic response of the reinforcements in compression [10].

For modelling purposes a law reflecting the compressibility behaviour of the reinforcement has to be entered. However, the experimentally determined compression curves depend on the strain rates applied during the test.

The model developed by Ouahbi et al. [1] predicts the evolution of the reinforcements thickness submitted to hydromechanical loads. Experimental permeability and compressibility laws are implemented in the model as entry parameters. compressibility curve corresponding to a hydromechanical solicitation determined experimentally. To this objective the numerical code developed by Ouahbi et al. [1] is used with an inverse method.

\section{EXPERIMENTAL PROCEDURES}

\subsection{Experimental device}

A device to establish hydromechanical loadings under various injection conditions such as pressure control or flow rate control and various compaction conditions such as stress or displacement control was set up. A schematic diagram of the device is shown in Figure 2.

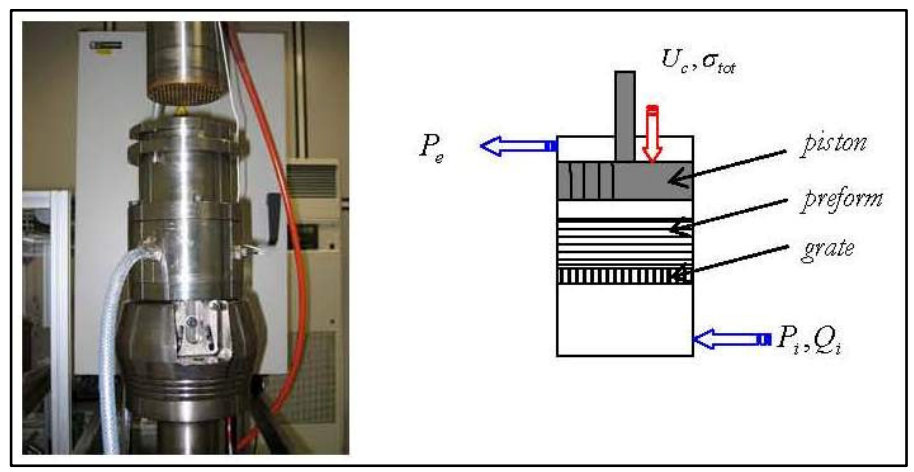

Fig.2. The HMz device

The $H M_{z}$ device consists of a stainless steel cylindrical pot within which a guided piston induces the exact amount of fibre compaction in the $z$ direction. The device is mounted on a universal testing machine (Instron 8802) to control the movement of the piston and therefore the force applied to the fibrous medium. The fluid is guided in the $z$ direction by perforated bronze grids. Test samples of fibrous preforms are placed between the two grids and the pressure is measured by sensors, placed below the lower grid. Despite of the fact that the device can be used to measure permeability and compressibility in a classical manner, its originality resides in the possibility of compressing the fibrous network at the same time as the fluid is injected through the fibres. It is therefore possible to establish hydromechanical coupling loads at stress or displacement conditions at different constant flow rates. 
The material used during this study is an E glass 5 harness satin weave. This material has an areal weight of $620 \mathrm{~g} / \mathrm{m}^{2}$ and an initial fibre volume fraction of $\sim 48 \%$. The thickness of an individual layer of fabric is $0.5 \mathrm{~mm}$. The fluid used in the experimental procedure is a silicon oil which viscosity is 0.1 Pa.s. A specially made cutter was machined to obtain accurate size circular preforms. A thin silicon seal is added to prevent preferential oil propagation on the edge of the samples along the cylinder wall. The different layers of fabric are superimposed and the yarns of each layers are disposed parallel to the corresponding yarns of the neighbouring fabric layer. Twenty layers of fabric are disposed for each test. The compaction velocity is ranged from 0.25 to $2 \mathrm{~mm} / \mathrm{min}$ for the compressive test. Under stress condition, hydromechanical test are conducted following ramps of $5 \mathrm{kN} / \mathrm{min}$ and $10 \mathrm{kN} / \mathrm{min}$ up to a load of $\sim 30 \mathrm{kN}$ where the load is held constant to observe eventual viscoelastic recovery.

A 6 litres syringe is placed on an Instron 5867 universal testing machine to control the flow rate imposed to the fibrous reinforcements. The flow rate value is controlled by the universal testing machine crosshead speed. For hydromechanical coupling tests, a constant flow rate $\left(6.710^{-6} \mathrm{~m}^{3} / \mathrm{s}\right)$ is obtained by keeping the syringe speed constant.

\section{RESULTS}

\subsection{Hydromechanical coupling under stress condition}

Under stress condition, the variation of thickness due to a constant mechanical stress rate is measured as a function of time. A fluid flow of constant flow rate is also applied to place the specimen of fabric under hydromechanical load. Figure 3 shows the thickness variation of same preforms submitted to two different stress rates ( 5 and $10 \mathrm{kN} / \mathrm{min}$ ) up to a load of $30 \mathrm{kN}$ or a stress of $3.8 \mathrm{MPa}$.

When the ramp of mechanical stress is applied, the two curves show a fast decrease in the reinforcement thickness over about 10 seconds with apparent constant speeds. During the first 10 seconds, the upper grid travels a distance of about $2 \mathrm{~mm}$ therefore

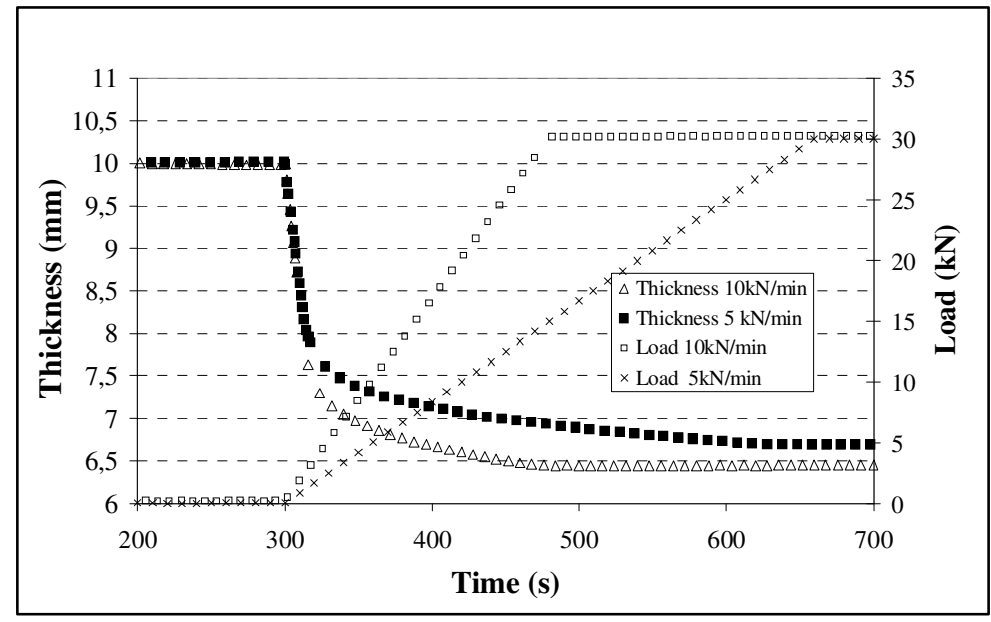

Fig.3. Hydromechanical loading under stress and flow rate conditions

conferring an average speed of $12 \mathrm{~mm} / \mathrm{min}$. Between $\mathrm{t}=310 \mathrm{~s}$ and $\mathrm{t}=480 \mathrm{~s}$ for the $10 \mathrm{kN} / \mathrm{min}$ curve and between $\mathrm{t}=310 \mathrm{~s}$ and $\mathrm{t}=660 \mathrm{~s}$ for the $5 \mathrm{kN} / \mathrm{min}$ curve, the piston still submitted to the same stress rate and same constant flow rate progressively slows down. However, the value of the thickness of preforms does not reach a constant value. The final compression speed measured for the curve submitted to the $5 \mathrm{kN} / \mathrm{min}$ stress rate is about $0.1 \mathrm{~mm} / \mathrm{min}$ before the load reaches a value of $30 \mathrm{kN}$. The final compaction speed measured for the curve submitted to the $10 \mathrm{kN} / \mathrm{min}$ stress rate is about $0.15 \mathrm{~mm} / \mathrm{min}$. This demonstrates that during the compression at constant stress rate, the speed of compaction changes from about 12 to $0.1 \mathrm{~mm} / \mathrm{min}$. In terms of micromechanisms, the acceleration of the lower grid (between $\mathrm{t} \sim 300$ and $\mathrm{t} \sim 310 \mathrm{~s}$ ) with increasing applied stress is probably due to a quick fibre rearrangement and filling up of the porosity. Then rearrangement of the fibres becomes probably more and more difficult due to a higher level of fibre compression and lower porosity.

Figure 3 also shows that the final thickness of the samples submitted to $10 \mathrm{kN} / \mathrm{min}$ stress ramp is lower than the sample submitted to a $5 \mathrm{kN} / \mathrm{min}$ ramp. This confirms that the hydromechanical loading (for both displacement and stress conditions) of a 5 harness satin glass weave exhibits a strong viscoelasticity.

\subsection{Inverse method/Compressibility curves}

An inverse method is implemented in Ouahbi et al. 's [1] model to establish the compressibility curves corresponding to the two hydromechanical curves 
The compressibility curves obtained from the inverse method modelling are compared to experimental curves determined with imposed compression velocities (between 0.25 to $2 \mathrm{~mm} / \mathrm{min}$ ) in Figure 4.

Figure 4 shows that the stresses required to compact saturated by the fluid fibrous preforms rises with an increasing compaction speed as already mentioned by Robitaille and Gauvin [11] for dry compression of satin glass weave. This is due to the viscoelastic behaviour of the studied preform.

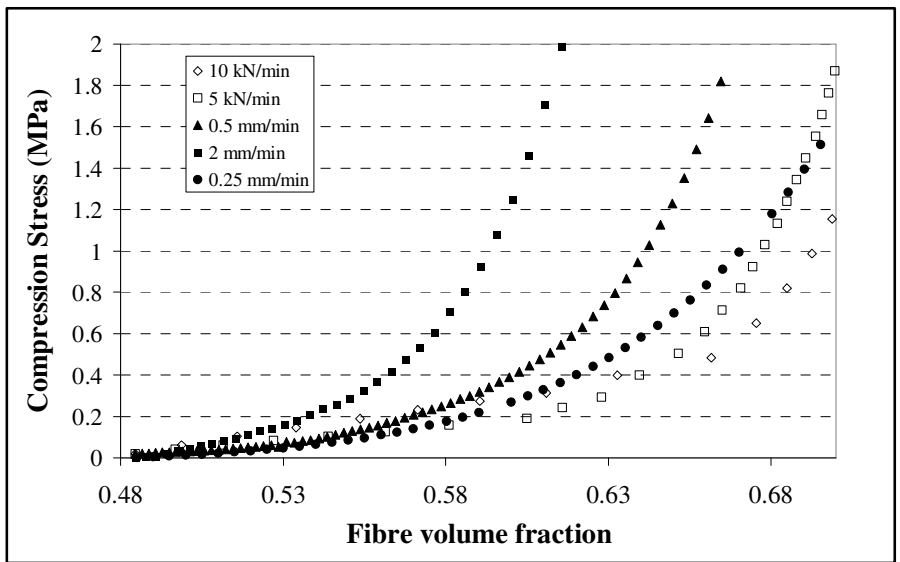

Fig.4. Comparison of experimental and numerical compressibility curves

The curves determined numerically from experimental hydromechanical coupling curves using Ouahbi et al.'s model with an inverse method shows similar behaviour than experimental curves determined with an imposed compression speed of $0.25 \mathrm{~mm} / \mathrm{min}$. This seems to indicate that the compressibility law required to model hydromechanical coupling is a curve that can be experimentally determined if a slow compression speed is imposed.

If the Toll and Manson [7] $b$ factor is considered to be fixed for a given preform because it is dependent of the reinforcement microstructure, then the coefficient $a$ should vary to accommodate the viscoelastic effects such as the ones observed with compression speed changes. It is therefore proposed to replace the constant $a$ by a viscoelastic function to establish a behaviour law that could take into account the effects induced by changes in the loading conditions.
A model initially used to simulate the effect of coupled hydromechanical load on composite preform is programmed with an inverse method to predict the compressibility behaviour of the reinforcements. An experimental device developed at Le Havre is used to apply hydromechanical loads to the preforms. Two ramps of stress are imposed to the preform and the evolution of the thickness measured as a function of time. The speed of thickness reduction is not constant and varies in the range 12 to $0.1 \mathrm{~mm} / \mathrm{min}$. Experimental and calculated-using-the-model compressibility curves are compared. The calculated curves show a behaviour corresponding to compressibility curves experimentally obtained with low compression speed $(\sim 0.25 \mathrm{~mm} / \mathrm{min})$.

\section{REFERENCES}

1. Ouahbi T, Saouab A, Bréard J, Ouagne P, Chatel S. Modeling of hydro-mechanical coupling in infusion processes. Comp Part A 38 (2007) 1646-1654.

2. Drapier S, Monate J, Elbouazzaoui O, Henrat $\mathrm{P}$, Characterization of transcient through-thickness permeabilities of non-crimped new concept (NC2) multiaxial fabrics. Comp. Part A (2005) 877-892.

3. Antonucci V, Giordano M, Nicolais L, Calabro A, Cusano A, Cutolo A, Inserra S. Resin flow monitoring in Resin Film Infusion process. Journal of Materials Processing Technology 143-144 (2003) 687-692.

4. Correia NC, Robitaille F, Long AC, Rudd CD, Simacek $\mathrm{P}$, Advani SG. Analysis of the vacuum infusion moulding process: I. Analytical formulation. Comp. Part A 36 (2005) 1645-56.

5 Lopatnikov S, Simacek P, Gillespie J, Advani SG. A closed form solution to describe infusion of resin under vacuum in deformable fibrous porous media. Model Simul Mater Sci Eng 12 (2004) 191-204.

6. Sommer JL, Mortensen A. Forced unidirectional infiltration of deformable porous media. J Fluid Mech. 22 (1996) 1205-22.

7. Toll S, Manson JAE. An analysis of the compressibility of fiber assemblies. In: Proceeding of the sixth International Conference on Fiber-Reinforced Composites, Institute of Materials, Newcastle upon Tyne, UK, 1994, p. 25/1-25/10.

8. Mehri D, Michaud V, Comte E, Manson JAE. Predicting the sizing dependent rigidity of glass fibre bundles in sheet moulding compounds. Comp Part A 37 (2006) 1773-1786.

9. Cadinot S. Aspects rhe'ologiques de la compressibilite' d'un renfort fibreux pour mate'riaux composites: e'tudes en compression et relaxation. These de Doctorat 2002. Universite du Havre.

10. Kelly PA, Umer R, Bickerton S. Viscoelastic response of dry and wet fibrous materials during infusion processes. Comp. Part A 37 (2006) 868-873.

11. Robitaille F, Gauvin R. Compaction of textile reinforcements for composites manufacturing. I: Review of experimental results. Polymer composites 19 (1998) (2): 198-216. 